\title{
LIVRO PUBLICADO
}

\section{Auxiliar do Oftalmologista}

\author{
Regina Carvalho de Sales Oliveira; Newton Kara José
}

Roca (São Paulo), 2000

O livro "Auxiliar do Oftalmologista" de autoria de Regina Carvalho de Sales Oliveira, Auxiliar de Oftalmologia e Pedagoga pela Universidade de São Paulo, e Newton Kara José, Professor Titular de Oftalmologia da Faculdade de Medicina da USP, é de extrema utilidade para todos os interessados em disseminar o conhecimento oftalmológico na equipe de saúde e aumentar o rendimento da mesma em benefício dos pacientes, dos próprios médicos e da sociedade brasileira.

O livro conta com 412 páginas e a colaboração de 34 especialistas e técnicos de diferentes áreas da Oftalmologia. São 34 capítulos que discutem o papel do auxiliar de oftalmologia, as principais bases fisiológicas, imunológicas e anatômicas do globo ocular bem como a anamnese e todas as doenças oculares mais importantes da maneira que o auxiliar do oftalmologista possa entender, aprender e ajudar. Uma importante parte do livro é dedicada aos exames realizados durante a consulta e seu complemento, incluindo tonometria, exoftalmometria, gonioscopia, biomicroscopia de segmento posterior, oftalmoscopia etc. bem como aplicação de laser em oftalmologia. Inclui também evidentemente lentes de contato, visão subnormal e aspectos importantes relacionados à psicologia do paciente e a prestação do serviço oftalmológico com alta qualidade, alto rendimento, menor custo e maior competitividade.

Trata-se, sem dúvida de um grande livro, de conhecimento obrigatório para integrantes de nossas equipes de saúde ocular.

Prof. Dr. Rubens Belfort Jr.

\section{Novidades na Internet!:?}

Agora no site CBO você tem disponível todas as informações na íntegra dos

Arquivos Brasileiros de Oitalmologia

httpa//w ww.cho.com.br/abo 